\title{
ON SUBMISSION OF COMMUNICATIONS FOR PUBLICATION
}

The Publishers and I must again ask the Authors to follow strictly the Instructions to Authors, printed on the inside back cover of each issue of BIORHEOLOGY. There have been delays of publication, because a communication accepted for publication on scientific merits had to be returned to the $\mathrm{Au}-$ thors for corrections and retyping, because of errors in presentation. Actually, such a technically faulty communication should never have been considered for review on scientific merits by the Editor, to whom it was submitted. Although we have cautioned our Editors, some of them or their secretarial assistants have overlooked the requirements, as given in the Instructions to Authors.

Some exrors in a manuscript, submitted for camera-ready printing, occur frequently and, therefore, I should point out to them in order to facilitate publication as rapidly as possible, after a Paper or Brief Communication has been accepted by an Editor. They concern the following points:

1. Preparation or laysheets should be used as much as possible. In case these sheets cannot be quickly secured by Authors, eager to get their work published without delay, the limitation in size of the typing area should be followed as described in the Instructions to Authors. The typing area on each sheet should be utilized as fully as possible.

2. Key Words are always necessary and must be placed as a footnote after the wording "Key Words:" on the Title Page and not on a separate sheet.

3. Running Titles of not more than 45 typewriter spaces must be provided by the Author on a separate sheet or written in blue pencil on the top of the Title Page.

4. Figures

a. Space of Figures on the preparation or laysheets must be provided, but not more than is necessary, and the legends will have to be placed next to or below the Figures.

b. The Figures should be clear either on a glossy photograph or in the original. They can never be smaller than the required size, but can be larger.

c. The lettering for each Figure has to be large enough to be easily readible after the $20 \%$ reduction which each manuscript sheet is subjected to.

d. On the back of each Figure, the names of the Authors and the number of the Figure should be placed lightly in pencil.

e. Figures cannot be placed in the text under Discussion.

5. The References must be followed in accordance to our Instructions to Authors. Surnames must be capitalized, the name of the journal and its volume must be underlined and in the case of a book, its title has to be underlined. If the book has particular Editors, their names must be provided in accordance with the Instructions. The last page number of a reference must be given together with the first. 
6. Double spacing or $1 \frac{1}{2}$ spacing is no longer permissible. Each text will need to be single-spaced. Each paragraph should begin with an indentation and should be separated from the following paragraph by double spacing. In this way a paragraph is clearly identified.

7. Regarding page charges, details are given in the Instructions to Authors. In case the communication exceeds the permissible number of pages, which are free of charge, the Authors are requested to submit a statement signed by them or their institution that the extra page charge of $50 \mathrm{U} . \mathrm{S}$. dollars per every 2 pages will be paid to the Publishers.

8. Each Editor must send two forms to the Authors, when a communication is accepted for publication. One of these forms, which contains the Reprint Order Form, notifies the Author(s) that the communication has been accepted, while the other is the Copyright Form. An Author must complete both forms and send them without delay to the Executive Editorial Office (EEO) and not to the Publishers. The EEO is under my direction and is located at the Laboratory of Biorheology, Polytechnic Institute of New York, 333 Jay Street, Brooklyn, NY 11201, USA. The Reprint Order Form must also be completed, whether or not the purchase of reprints is requested.

We have only emphasized the need for corrections of errors which are usually made by the Authors. However, there are other points which are given under the Instructions to Authors which must also be strictly adhered to by the Authors. The Authors and their secretarial assistants must, therefore, acquaint themselves fully with the Instructions to Authors before the typing of a manuscript in camera-ready form. After the notification of acceptance of a communication by an Editor, the Authors must act also in accordance with the Instructions, some of which are reemphasized in the Editorial.

It should be pointed out that only the last revision of June 1979 of our Instructions to Authors contained in each issue beginning with Volume 16, Number 3 are valid. 